\title{
Whistle characteristics and daytime dive behavior in pantropical spotted dolphins (Stenella attenuata) in Hawai'i measured using digital acoustic recording tags (DTAGs)
}

\author{
Tammy L. Silva ${ }^{\text {a) }}$ \\ Biology Department, University of Massachusetts Dartmouth, 285 Old Westport Road, Dartmouth, \\ Massachusetts 02747, USA \\ T. Aran Mooney and Laela S. Sayigh \\ Biology Department, Woods Hole Oceanographic Institution, MS\#50, 266 Woods Hole Road, \\ Woods Hole, Massachusetts 02543, USA \\ Peter L. Tyack \\ Sea Mammal Research Unit, Department of Biology, University of St. Andrews, East Sands, \\ St. Andrews KY16 8LB, United Kingdom \\ Robin W. Baird \\ Cascadia Research Collective, 218 1/2 West 4th Avenue, Olympia, Washington 98501, USA \\ Julie N. Oswald \\ Bio-Waves, Inc., 364 2nd Street, Suite \#3, Encinitas, California 92024, USA
}

(Received 3 August 2015; revised 16 June 2016; accepted 20 June 2016; published online 19 July 2016)

This study characterizes daytime acoustic and dive behavior of pantropical spotted dolphins (Stenella attenuata) in Hawai'i using $14.58 \mathrm{~h}$ of data collected from five deployments of digital acoustic recording tags (DTAG3) in 2013. For each tagged animal, the number of whistles, foraging buzzes, dive profiles, and dive statistics were calculated. Start, end, minimum, and maximum frequencies, number of inflection points and duration were measured from 746 whistles. Whistles ranged in frequency from $9.7 \pm 2.8$ to $19.8 \pm 4.2 \mathrm{kHz}$, had a mean duration of $0.7 \pm 0.5 \mathrm{~s}$ and a mean of $1.2 \pm 1.2$ inflection points. Thirteen foraging buzzes were recorded across all tags. Mean dive depth and duration were $16 \pm 9 \mathrm{~m}$ and $1.9 \pm 1.0 \mathrm{~min}$, respectively. Tagged animals spent the majority of time in the upper $10 \mathrm{~m}(76.9 \% \pm 16.1 \%)$ of the water column. Both whistle frequency characteristics and dive statistics measured here were similar to previously reported values for spotted dolphins in Hawai'i. Shallow, short dive profiles combined with few foraging buzzes provide evidence that little spotted dolphin feeding behavior occurs during daytime hours. This work represents one of the first successful DTAG3 studies of small pelagic delphinids, providing rare insights into baseline bioacoustics and dive behavior. (ㅇ 2016 Acoustical Society of America.

[http://dx.doi.org/10.1121/1.4955081]

[WWA]

Pages: $421-429$

\section{INTRODUCTION}

Baseline data on bioacoustics and dive behavior are limited for many marine mammal species, but are important for studies of ecology and behavior, as well as for assessing the potential for anthropogenic impacts on these animals. Dive data may provide insights into foraging behavior and how animals use the water column, which may be used to inform development of acoustic deterrent devices and alterations to fishing practices or gear to reduce marine mammal bycatch (Westgate et al., 1995; Baird et al., 2001; Mooney et al., 2007; Linnenschmidt et al., 2013). Basic acoustic data may provide informative context for dive behavior (Watwood et al., 2006) and concurrent sampling of these data types, as with digital acoustic recording tags, can elucidate responses to anthropogenic noise (Tyack et al., 2011).

\footnotetext{
a)Electronic mail: tsilva4@umassd.edu
}

Baseline acoustic data are also necessary to inform passive acoustic monitoring (PAM), which is a leading method to study marine mammal occurrence, abundance, and habitat use (Jensen et al., 2009; van Parijs et al., 2009; Hawkins, 2010; Hatch et al., 2012; Marques et al., 2013; Risch et al., 2013). The development of automated detection and realtime monitoring systems (e.g., Oswald et al., 2007; Baumgartner and Mussoline, 2011) can improve the capabilities and cost-effectiveness of PAM-based surveys by reducing the staffing requirements at sea compared to visual sightings data. However, these approaches require the capability to classify sounds produced by marine mammals to species. Training and validation of classifiers require acoustic data from known species, and some PAM survey methods require call rates from individual animals. These data can be difficult to collect, especially from pelagic animals that may occur in mixed-species groups. Here, we report on one of the first successful efforts to tag small odontocetes with digital 
acoustic recording tags (DTAGs; Johnson and Tyack, 2003), an approach that promises to increase knowledge of baseline acoustic and dive behavior of these difficult to study species, and has potential to improve interpretation of PAM data, inform detector/classifier development and aid assessment of anthropogenic impacts.

Pantropical spotted dolphins (Stenella attenuata) are small odontocetes found in lower latitude waters worldwide. Most information about this species comes from studies in the eastern tropical Pacific (ETP) where there are significant interactions with the tuna purse seine fishery (Wade et al., 2007; Scott and Chivers, 2009). In the ETP, pantropical spotted dolphins occur in large groups numbering in the hundreds to thousands of individuals (Scott and Cattanach, 1998). These groups can have large home ranges, sometimes traveling more than $100 \mathrm{~km} /$ day (Leatherwood and Ljungblad, 1979; Scott and Cattanach, 1998). Dive patterns are consistent with nocturnal feeding behavior, with nighttime dives being deeper and longer than daytime dives (Scott and Chivers, 2009). In Hawai' $i$, spotted dolphins are typically found in smaller groups (60-65 individuals), as compared to the ETP (Barlow, 2006; Baird et al., 2013), though group sizes ranging from 1 to 400 individuals have been documented (Baird et al., 2013; Baird, 2016). Early population assessments using photo-ID and scarring patterns suggested that island-associated pantropical spotted dolphins have smaller home ranges than pelagic populations (Baird et al., 2001). Limited movement of pantropical spotted dolphins in Hawai'i was also supported by recent work documenting three genetically distinct populations around the main Hawaiian Islands (Courbis et al., 2014), which have been recognized as distinct stocks by the National Marine Fisheries Service (Carretta et al., 2014). Like ETP pantropical spotted dolphins, those in Hawai' ${ }^{i}$ also perform longer and deeper dives at nighttime, consistent with nocturnal feeding (Baird et al., 2001).

There are few studies of acoustic signals from pantropical spotted dolphin. Like many other delphinids, this species produces echolocation clicks, whistles, and burst-pulsed sounds (Lammers et al., 2003). Oswald et al. (2003) quantified whistle characteristics of ETP pantropical spotted dolphins, reporting minimum and maximum frequencies of 8.2 and $19.7 \mathrm{kHz}$, respectively. A combined assessment of whistle characteristics from pantropical spotted dolphins in the ETP and in Hawai 'i found minimum and maximum frequencies of 8.4 and $18.0 \mathrm{kHz}$, respectively (Oswald et al., 2007). However, because whistles from these populations were combined, the extent to which these parameters may vary among populations is not known; geographic variation in whistle characteristics has been documented in other delphinid species and could exist for pantropical spotted dolphins (e.g., Morisaka et al., 2005; Ansmann et al., 2007; May-Collado and Wartzok, 2008; Hawkins, 2010).

Digital acoustic recording tags present a powerful way to study the vocal repertoire and underwater behavior of cetaceans. DTAGs, equipped with suction cup attachments, hydrophones and multiple sensors (depth, accelerometers, magnetometers), record the sounds an animal produces and hears as well as coincident movement and depth. DTAGs have been deployed on multiple cetacean taxa including various baleen, beaked, and pilot whales (reviewed in Johnson et al., 2009). The latest version of the tag, the DTAG3, was developed for attachment to smaller odontocetes and was recently used to study the acoustic repertoire of melonheaded whales (Peponocephala electra; Kaplan et al., 2014). The DTAG3 has yet to be utilized on many species of small odontocetes, despite their relative abundance and the potential influence of noise exposure on large numbers of individuals. This work presents analyses of some of the first DTAG3 data collected from a small, pelagic delphinid species. Our aims were to gather baseline information about bioacoustics and dive behavior of pantropical spotted dolphins in Hawaiian waters and to assess similarity between data collected using DTAG3s and other recording systems (Baird et al., 2001; Oswald et al., 2007).

\section{METHODS}

\section{A. Field work}

Data were collected in May 2013 off the west (leeward) side of the island of Hawai' $\mathrm{i}$, USA [Fig. 1(a)] using field methods as described by Baird et al. (2013). Briefly, surveys and tagging efforts were conducted from an $8.2 \mathrm{~m}$ Boston Whaler. Within leeward Hawai'i Island waters, areas of operation were primarily driven by sea conditions, with attempts made to remain in areas of Beaufort 3 or less and with relatively short swell. Visual observations to spot groups of odontocetes were made $360^{\circ}$ around the vessel. A global positioning system (GPS) logged locations every $5 \mathrm{~min}$. All groups of detected odontocetes were approached for species identification, to record GPS location, and to estimate group size. Groups were defined using an $800 \mathrm{~m}$ chain rule (Smolker et al., 1992), where animals within $800 \mathrm{~m}$ of each other were considered to be part of the same group. Minimum, maximum, and best estimates of group size were made by consensus of experienced observers on the vessel (four to six observers were on the vessel on any given day). Photographs were taken of individuals for future photo-identification and population studies (e.g., Aschettino et al., 2012).

In order to apply DTAG3s, the boat gradually approached subgroups, and allowed the animals to bowride. When an animal surfaced near the bow, the suctioncup DTAG3 could be attached with a carbon-fiber pole [Figs. 1(b) and 1(c)]. Tags sampled stereo audio at $500 \mathrm{kHz}$, with concurrent sampling at $50 \mathrm{~Hz}$ of threedimensional accelerometers, magnetometers, and depth. After tagging, the tag boat generally moved away from the tagged animal (ca. several hundred meters) to limit any potential influence on behavior and reduce the boat noise on the acoustic tag record. Tag attachment was monitored by listening to the intermittent very high frequency (VHF) radio pulse of the surfacing tagged animal. The boat stayed with the group (which could be dispersed over several kilometers) to observe group behavior throughout the encounter, and until the tag was released and retrieved. 

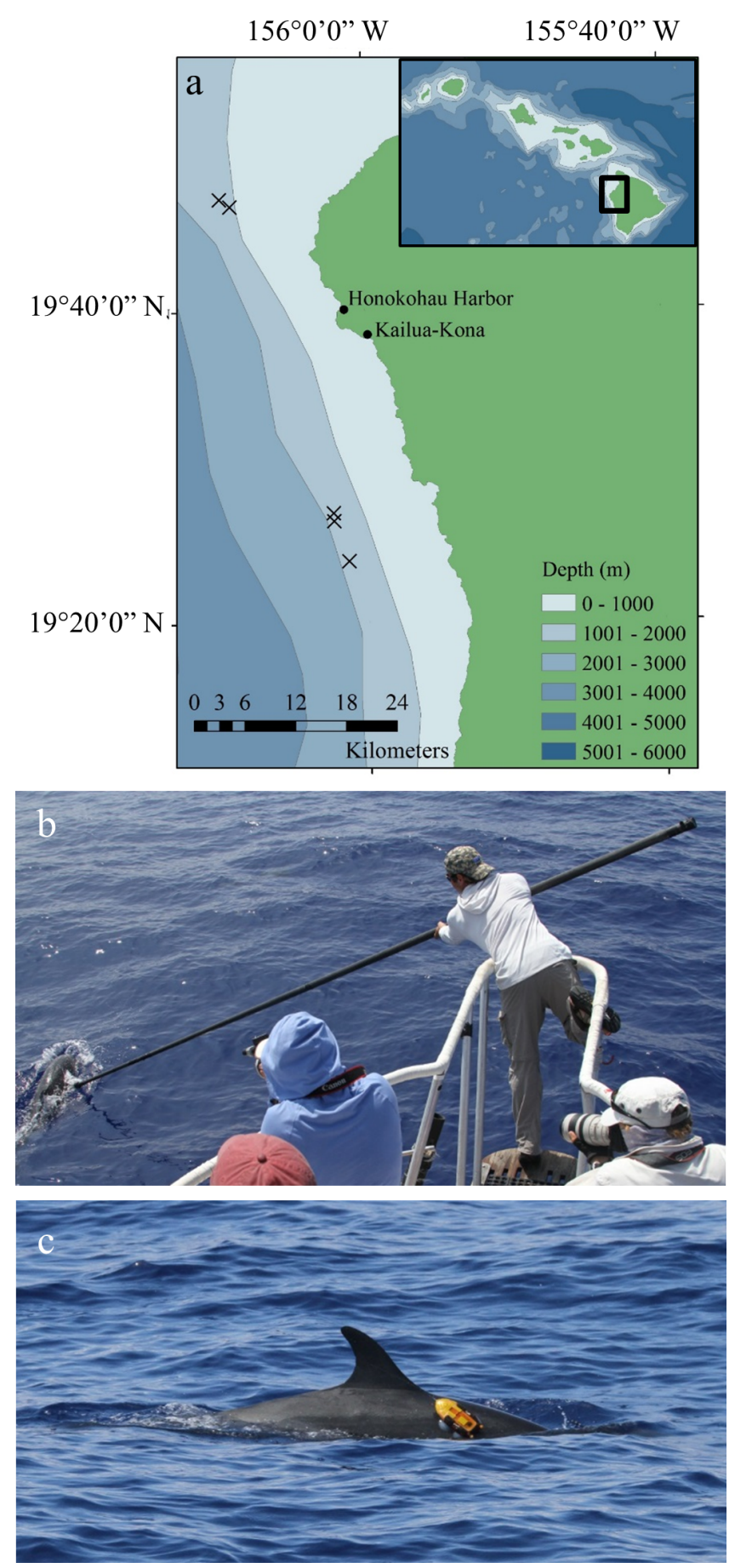

FIG. 1. (Color online) Tagging of pantropical spotted dolphins (Stenella attenuata). (a) DTAG3 tagging locations. The northern and southern clusters of locations represent tagging on the two different days. (b) Attaching the DTAG3. Photo credit: Amy Van Cise. (c) Pantropical spotted dolphin with DTAG3 attached. Photo credit: Amy Van Cise. Photos taken under NMFS permit \# 15530, Cascadia Research Collective. Map courtesy of Hawai' $i$ statewide GIS Program.

\section{B. Whistle identification}

Acoustic data were initially analyzed in MATLAB (MathWorks, Natick, MA) using a toolbox designed for DTAG3 analyses (available at soundtags.st-andrews.ac.uk/ dtags/dtag-3/). The acoustic recording for each tag was viewed as consecutive 10-s spectrograms [fast Fourier transform (FFT) size 1024 samples, Hamming window, 50\% overlap], and start and end times of all visible whistles were marked. A whistle was defined as a tonal, frequency modulated signal greater than $0.1 \mathrm{~s}$ in duration (Caldwell and Caldwell, 1970).

Whistles were visually selected for further analysis using criteria defined by Bazua-Duran and $\mathrm{Au}$ (2002). Whistles that met these criteria had a good signal to noise ratio, a discernible contour with distinct start and end points and little overlap with more than two other whistles. Whistles were extracted using a custom MATLAB script and saved as individual sound files for further analysis (see below).

Tag deployments on the same day overlapped in time and space, resulting in some whistles being recorded on multiple tags. If duplicate whistles were selected for analysis, spectral and temporal measurements were taken only from the whistle of highest amplitude (based on visual inspection of spectrograms). No whistles were measured more than once.

\section{Whistle characteristics and comparisons}

Whistles selected for further study were analyzed in Raven Pro 1.5 beta version build 21 (Charif et al., 2010; Cornell Lab of Ornithology, Ithaca, NY). Individual whistle files were viewed as spectrograms (2048 FFT, Hamming window, $75 \%$ overlap) with frequency and time resolutions of $244 \mathrm{~Hz}$ and $1.0 \mathrm{~ms}$, respectively. A selection box was manually drawn around the fundamental frequency of each whistle. Whistle duration was measured using the length of the selection box. The peak frequency contour (PFC) tool was then used to trace the fundamental frequency of the whistle contour. The PFC tool traces signals according to the points of peak energy along the contour and reports the contour trace as a vector of frequency point measurements. The PFC contour tool would occasionally track portions of higher intensity harmonics. In those cases, the original selection box was split into multiple selections allowing the user to manually adjust each selection box to more tightly encompass the fundamental frequency and eliminate harmonic portions. The user could then view the PFC whistle trace of all selections to ensure that the entire fundamental frequency was traced and could compare the PFC whistle trace of each selection box to obtain the measurements described below.

Using the PFC whistle trace, start frequency, end frequency, minimum frequency, maximum frequency, and number of inflection points were measured from the fundamental frequency of each whistle. These parameters were chosen to provide a comparison with previous studies. Inflection point was defined as a change from positive to negative or negative to positive slope with zero considered a positive value. Frequency range was also calculated for each whistle and was defined as the difference between minimum and maximum frequency in that whistle.

To our knowledge, Oswald et al. (2007) is the only previous study to measure whistle characteristics of pantropical spotted dolphins in Hawaiian waters. In order to test whether measurements of whistle characteristics are similar between whistles recorded with a towed array (as in Oswald et al., 
2007) and DTAG3s (our study), we used Wilcoxon tests with a Bonferroni correction to compare each of our whistle characteristics to characteristics measured from a subset of whistles from Oswald et al. (2007) that were also recorded off the west side of Hawai' $i$.

\section{Foraging and dive behavior}

As a measure of echolocation-based foraging activity by the tagged animal (hereafter referred to as the "focal" animal), we quantified the number of focal terminal buzzes that followed focal echolocation clicks on each tag. Echolocation-based foraging activity has been described as regularly spaced echolocation clicks that decrease in interclick interval and end with a terminal buzz, which is characterized by a rapidly increasing click rate, presumably during the final phase of prey capture (Johnson et al., 2004; Aguilar Soto et al., 2008; Linnenschmidt et al., 2013; Wisniewska et al., 2016). The physical attachment of the tag to the animal's body allows coupling of low frequency energy $(<15 \mathrm{kHz})$ from the body to the tag, therefore, focal echolocation clicks and buzzes can be identified spectrally based on the presence of low frequency energy (Zimmer et al., 2005; Johnson et al., 2006). The number of apparent terminal buzzes on each tag was documented during the initial visual inspection of acoustic data using the DTAG3 toolbox and the same spectrogram settings. Occurrences of buzzes on each tag were plotted on each dive profile.

MATLAB scripts from the DTAG3 toolbox were used to create dive profiles for each tagged animal. For dives to depths $>5 \mathrm{~m}$ (Baird et al., 2001), duration, rate (dives/h), and depth were computed. The percentage of time spent in $5 \mathrm{~m}$ depth bins as well as the percentage of time spent in the upper $10 \mathrm{~m}$ was calculated for each tagged animal and for all animals combined.

\section{RESULTS}

Five DTAG3 deployments were made across two encounters. One encounter was on May 26, 2013 (two deployments) with an estimated 400 individuals spread over an area of approximately $3000 \mathrm{~m}$ by $2000 \mathrm{~m}$, while the other was on May 27, 2013 (three deployments) with an estimated 140 individuals spread out over an area of approximately $500 \mathrm{~m}$ by $1600 \mathrm{~m}$ (Fig. 1). Both groups consisted exclusively of pantropical spotted dolphins. When the groups were first encountered the initial behavior noted for both was feeding, with rapid changes in direction indicative of fish chases, flying fish seen associated with the dolphins, and feeding seabirds associated with the groups. During the first encounter no other vessels were present, but on the second day there were between six and 13 fishing vessels associated with the dolphins, primarily trolling through the group attempting to catch yellowfin tuna.

The behavior of focal animals was observed before, during (reaction to tagging) and, when possible, after tagging. Pre-tagging behavior of tagged animals included traveling or bowriding (four animals) or milling (one animal). Reactions to tagging included a fast dive (two animals), an acceleration (two animals), and a flinch accompanied by acceleration (one animal). Three out of five tagged animals quickly (within ca. $5 \mathrm{~s}$ ) resumed pre-tagging behavior. Two animals were not observed after tagging and their post-tagging behavior was thus not documented. Tag attachments were often toward the flank or peduncle due to the speed and relatively small size of the animals. All tags were deployed between 09:30 and 11:30 local time (Table I). The shortest and longest tag deployments (h:min) were 0:25 and 5:58, respectively (Table I).

A total of 8632 whistles were marked from all five tags; some examples are shown in Fig. 2(a). The vast majority of these whistles were not used for analysis due to overlap with other whistles, clicks, boat noise and flow noise; 746 loud and clear whistles, spread unevenly across the five tags, were selected for analyses (Table I). Whistle parameters are given in Table II. In general, whistles lasted an average of $0.7 \pm 0.5 \mathrm{~s}$, contained frequencies ranging from approximately $10-20 \mathrm{kHz}$ and tended to increase in frequency over time, and contained 1 (mean 1.2) inflection point (Table II). These data were compared to a subset of whistles from Oswald et al. (2007) $(n=46)$, which had a mean duration of $0.9 \pm 0.4 \mathrm{~s}$ and frequencies ranging from approximately 9-20 kHz (Table II). Wilcoxon tests with Bonferroni correction showed no significant differences for any whistle parameters measured in the current study and compared with the subset of whistles from Oswald et al. (2007). Table II summarizes published whistle parameter measurements for several Stenella species and populations. Whistle parameters measured here were similar to those reported for pantropical spotted dolphins in past studies. Notably, frequency ranges for pantropical spotted dolphins reported here and by Oswald et al. (2003) are both substantially higher than values reported for other Stenella species (Table II).

TABLE I. Summary of DTAG3 deployment details including tag identification number (which corresponds to Julian day, 146= May 26, 147= May 27), local time of attachment (tag-on time), attachment duration, total numbers of annotated and analyzed whistles and dive statistics.

\begin{tabular}{lcccccccccccc}
\hline \hline & $\begin{array}{c}\text { Tag-on } \\
\text { time } \\
\text { (local) }\end{array}$ & $\begin{array}{c}\text { Attachment } \\
\text { duration } \\
\text { (h: } \text { min) }\end{array}$ & $\begin{array}{c}\text { Whistles } \\
\text { annotated }\end{array}$ & $\begin{array}{c}\text { Whistles } \\
\text { analyzed }\end{array}$ & Buzzes & Dives & $\begin{array}{c}\text { Dive } \\
\text { rate } \\
\text { (dives/h) }\end{array}$ & $\begin{array}{c}\text { Mean } \\
\text { Depth } \\
\text { (m) }\end{array}$ & $\begin{array}{c}\text { Max } \\
\text { Depth } \\
\text { (m) }\end{array}$ & $\begin{array}{c}\text { Mean Dive } \\
\text { Duration } \\
\text { (min) }\end{array}$ & $\begin{array}{c}\text { Max Dive } \\
\text { Duration } \\
(\mathrm{min})\end{array}$ & $\begin{array}{c}\text { Percent time } \\
\text { in upper } \\
10 \mathrm{~m}\end{array}$ \\
\hline sa146a & $09: 45$ & $2: 09$ & 1180 & 149 & 8 & 28 & 13.2 & $9(4)$ & 20 & $0.7(0.5)$ & 1.8 \\
sa146b & $10: 03$ & $1: 39$ & 788 & 143 & 3 & 37 & 22.6 & $12(6)$ & 35 & $1.7(0.6)$ & 2.7 & 76 \\
sa147b & $10: 10$ & $0: 25$ & 203 & 57 & 0 & 9 & 21.8 & $13(4)$ & 15 & $1.3(0.5)$ & 1.7 & 78.5 \\
sa147c & $10: 19$ & $4: 24$ & 3776 & 199 & 0 & 53 & 12.0 & $11(5)$ & 25 & $2.1(0.8)$ & 4.4 & 83.2 \\
sa147d & $11: 19$ & $5: 58$ & 2685 & 198 & 2 & 86 & 14.4 & $23(9)$ & 48 & $2.4(1.1)$ & 4.8 & 51.4 \\
All tags & & $14: 35$ & 8632 & 746 & 13 & 213 & 14.7 & $16(9)$ & 48 & $1.9(1.0)$ & 4.4 & $76.9(16.1)$ \\
\hline \hline
\end{tabular}




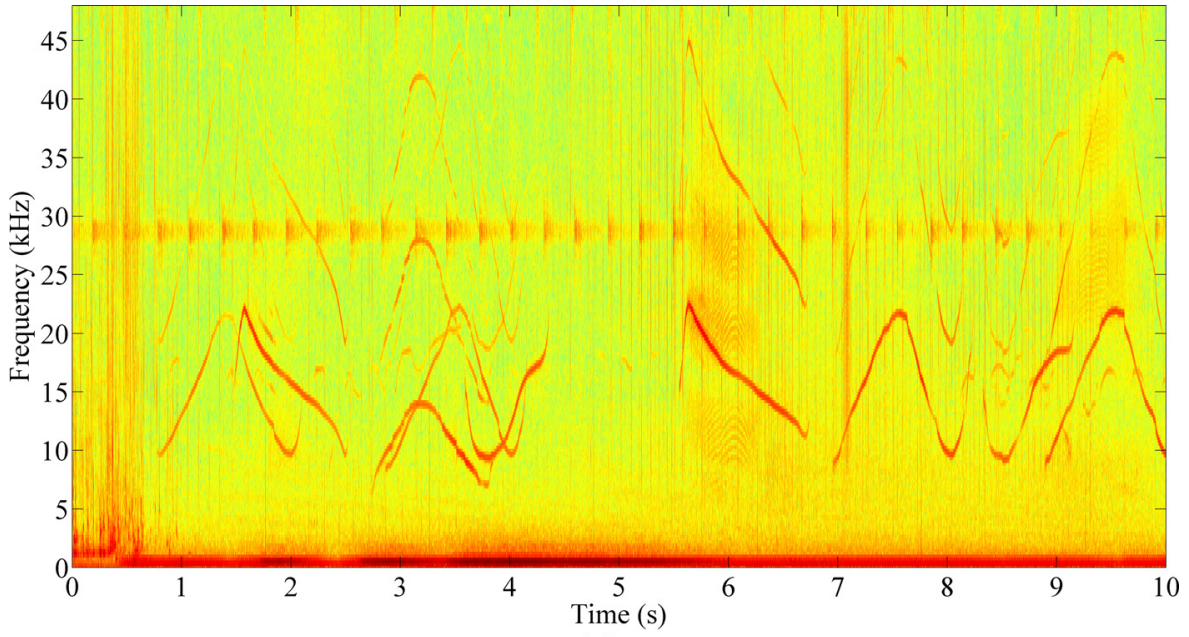

(a)

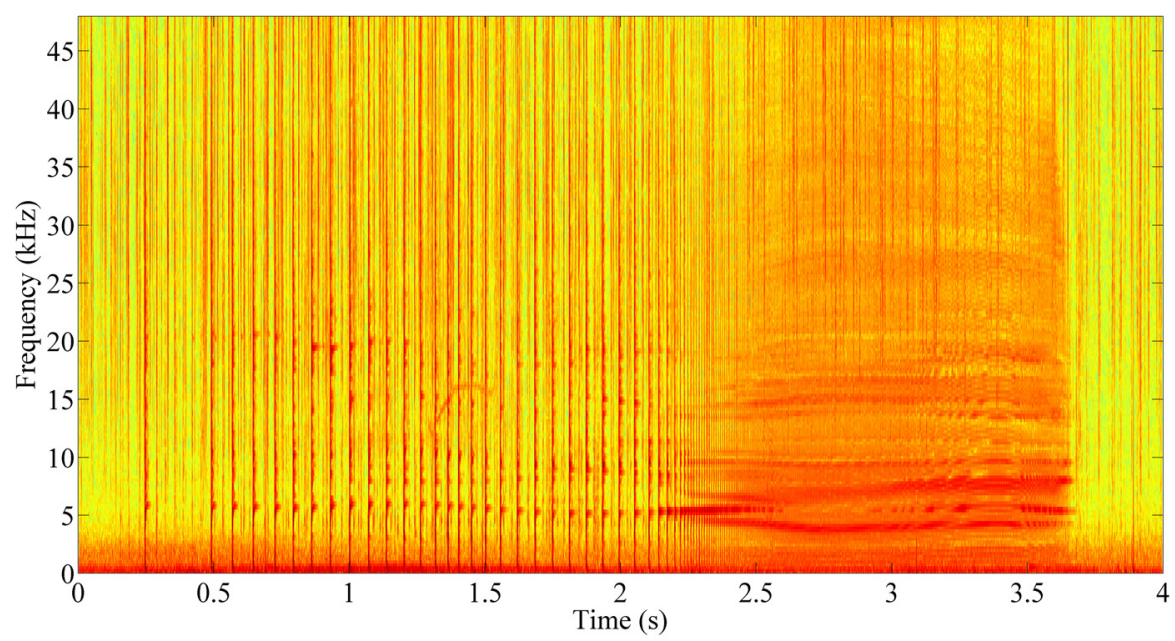

(b)
FIG. 2. (Color online) Examples of DTAG3-recorded pantropical spotted dolphin vocalizations (2048 FFT, Hanning window, 95\% overlap). (a) Whistles. (b) Focal echolocation clicks followed by an apparent terminal buzz. Note the different time axes.
A total of 13 buzzes were recorded on all tags [Fig. 2(b), Table I]. The number of buzzes recorded on individual tags ranged from zero to eight (Table I). Dive profiles were plotted for all tagged animals (Fig. 3) and dive statistics were calculated for all excursions below $5 \mathrm{~m}$ (Table I). All tagged animals spent the majority of time in the upper $5 \mathrm{~m}$ of the water column, although dive patterns differed among dolphins (Figs. 3 and 4). Mean dive depth was $16 \pm 9 \mathrm{~m}$, with maximum depths ranging from 15 to $48 \mathrm{~m}$. Mean dive duration was $1.9 \pm 1.0 \mathrm{~min}$, with maximum durations ranging from 1.7 to $4.8 \mathrm{~min}$. Tagged animals spent an average of $76.9 \pm 16.1 \%$ of time in the upper $10 \mathrm{~m}$ of the water column (Table I). Buzzes were recorded at the surface and at depth (Fig. 3). For animals sa146a and sa146b, $7.1 \%$ and $8.1 \%$ of dives contained buzzes, respectively. No dives recorded for animal sa147d contained buzzes and no buzzes were recorded for animals sa147b and sa147c. The mean depth of buzz production was $5 \pm 8 \mathrm{~m}$.

\section{DISCUSSION}

This paper describes some of the first data collected with DTAG3s from small pelagic odontocetes. Parameters of spotted dolphin whistles recorded with DTAG3s off Hawai' $i$ were not significantly different from those recorded by Oswald et al. (2007) in the same area, despite differences in recording methods; Oswald et al. (2007) used an array of hydrophones towed behind a ship in their study. The similarity in these results suggest that DTAG3 data may also be used as an additional data source for the development of acoustic classification algorithms, which have traditionally been created using towed array data (Oswald et al., 2007). However, some additional testing of potential differences resulting from these two recording methods should be used when initially integrating DTAG3 data into such classifiers; we suggest additional data collection to corroborate the results here, as the five recordings reported here from two different groups of animals over two encounters represent a small sample size. Additional data collection from pantropical spotted dolphins and other species using DTAG3s and comparisons with data collected using towed arrays would help test for similarities between these platforms which would support incorporation of DTAG3 data into automated detection and classification algorithms.

Baseline bioacoustic data are essential for development of automated detection and classification techniques, but these data can also improve PAM studies of habitat use and occurrence patterns. However, variability in species' whistle characteristics caused by population differences can make classification to species challenging for PAM 
TABLE II. Comparison of Stenella spp. whistle characteristics among studies. Mean values of whistle characteristics with standard deviations in parentheses are listed. Note: Bazua-Duran and Au (2002) mention use of a different definition of inflection points for S. longirostris whistles that was not comparable to the other studies and is listed here as "not reported."

\begin{tabular}{|c|c|c|c|c|c|c|c|c|c|}
\hline Study & $n$ & $\begin{array}{l}\text { Start } \\
\text { frequency } \\
(\mathrm{kHz})\end{array}$ & $\begin{array}{l}\text { End } \\
\text { frequency } \\
(\mathrm{kHz})\end{array}$ & $\begin{array}{l}\text { Minimum } \\
\text { frequency } \\
\quad(\mathrm{kHz})\end{array}$ & $\begin{array}{l}\text { Maximum } \\
\text { frequency } \\
\quad(\mathrm{kHz})\end{array}$ & $\begin{array}{l}\text { Mean } \\
\text { frequency } \\
(\mathrm{kHz})\end{array}$ & $\begin{array}{l}\text { Frequency } \\
\text { range } \\
(\mathrm{kHz})\end{array}$ & $\begin{array}{l}\text { Duration } \\
\text { (s) }\end{array}$ & $\begin{array}{l}\text { Inflection } \\
\text { points }\end{array}$ \\
\hline $\begin{array}{l}\text { Stenella attenuata } \\
\text { Hawai'i Island } \\
\text { This study }\end{array}$ & 746 & $11.2(3.9)$ & $16.8(5.3)$ & $9.7(2.8)$ & $19.8(4.2)$ & not measured & $10.1(4.9)$ & $0.7(0.5)$ & $1.2(1.2)$ \\
\hline $\begin{array}{l}\text { Stenella attenuata } \\
\text { Hawai‘i Island } \\
\text { Oswald et al. (2007) }\end{array}$ & 46 & $10.8(3.8)$ & $15.3(6.9)$ & $9.1(2.2)$ & 20.7 (4.7) & not reported & not reported & $0.9(0.4)$ & $1.4(1.2)$ \\
\hline $\begin{array}{l}\text { Stenella attenuata } \\
\text { ETP } \\
\text { Oswald et al. (2003) }\end{array}$ & 97 & 9.5 (2.9) & $15.3(5.2)$ & $8.2(1.7)$ & $18.7(3.0)$ & not reported & $10.6(3.3)$ & $0.9(0.4)$ & $1.9(1.8)$ \\
\hline $\begin{array}{l}\text { Stenella attenuata } \\
\text { ETP and Hawaiian } \\
\text { Island chain } \\
\text { Oswald et al. (2007) }\end{array}$ & 399 & 9.92 (3.94) & $14.92(5.66)$ & $8.41(2.39)$ & 17.99 (4.69) & not reported & not reported & $0.75(0.38)$ & $1.29(1.45)$ \\
\hline $\begin{array}{l}\text { Stenella longirostris } \\
\text { Hawai'i Island } \\
\text { Bazua-Duran and Au (2002) }\end{array}$ & 961 & $12.02(3.66)$ & $14.91(3.80)$ & $10.68(2.68)$ & $16.50(3.54)$ & not reported & $5.82(3.67)$ & $0.449(0.372)$ & not reported \\
\hline $\begin{array}{l}\text { Stenella longirostris } \\
\text { Hawai'i } \\
\text { Lammers et al. (2003) }\end{array}$ & 167 & not reported & not reported & $10.1(2.5)$ & $17.4(3.0)$ & $13.8(2.3)$ & $7.3(3.9)$ & $0.66(0.36)$ & not reported \\
\hline $\begin{array}{l}\text { Stenella frontalis } \\
\text { southeastern Brazil-coastal } \\
\text { Azevedo et al. (2010) }\end{array}$ & 1092 & $8.85(3.21)$ & $12.76(3.80)$ & $8.04(2.51)$ & $13.58(3.64)$ & $10.81(2.63)$ & $5.53(3.52)$ & $0.36(0.29)$ & $0.74(1.30)$ \\
\hline $\begin{array}{l}\text { Stenella frontalis } \\
\text { Bahamas } \\
\text { Lammers et al. (2003) }\end{array}$ & 220 & not reported & not reported & $7.1(1.5)$ & $14.5(2.5)$ & $10.9(2.0)$ & $7.4(2.9)$ & $0.44(0.30)$ & not reported \\
\hline $\begin{array}{l}\text { Stenella coeruleoalba } \\
\text { ETP } \\
\text { Oswald et al. (2003) }\end{array}$ & 91 & $10.2(3.7)$ & $12.0(2.8)$ & $8.1(1.6)$ & $14.8(3.5)$ & not reported & $6.8(3.7)$ & $0.8(0.3)$ & $1.9(2.1)$ \\
\hline $\begin{array}{l}\text { Stenella coeruleoalba } \\
\text { ETP and Hawaiian } \\
\text { Island chain } \\
\text { Oswald et al. (2007) }\end{array}$ & 401 & $10.80(3.96)$ & $12.01(3.40)$ & $8.48(2.21)$ & $14.98(3.61)$ & not reported & not reported & $0.69(0.35)$ & $1.84(1.82)$ \\
\hline
\end{tabular}

studies and may limit classifier use to specific geographic regions. Notably, such population-level variability has been found within several different delphinid species. For example, whistle frequency parameters differ among populations of short-beaked common dolphins (Delphinus delphis; Ansmann et al., 2007), Indo-Pacific bottlenose dolphins (Tursiops aduncus; Hawkins, 2010), and common bottlenose dolphins (Tursiops truncatus; May-Collado and Wartzok, 2008). Furthermore, spectral and temporal whistle characteristics and vocal behavior are known to be influenced by factors such as group size, whistle type, behavior, stress and ambient noise levels (Morisaka et al., 2005; Ansmann et al., 2007; May-Collado and Wartzok, 2008; Rankin et al., 2008; Esch et al., 2009; Hawkins, 2010), which all may vary across time and space. Around the main Hawaiian Islands, three insular populations of pantropical spotted dolphins have recently been designated: an $\mathrm{O}^{`}$ ahu stock, a 4-Island stock and a Hawai' $\mathrm{i}$ Island stock (Caretta et al., 2014). Whistles in the current study and the subset of whistles from Oswald et al. (2007) were recorded off the west side of Hawai'i Island, both within the stock boundary for the Hawai'i Island stock (Caretta et al., 2014) and no significant differences were found; however, the extent to which differences exist among these three populations and the Hawai' $i$ pelagic stock, or with ETP populations, is currently unknown. Interestingly, the frequency range of whistles measured here and those measured by Oswald et al. (2003) are at least $2.7 \mathrm{kHz}$ higher than frequency ranges reported for other Stenella species (Table II), suggesting that frequency range could be an important parameter for species identification. Future DTAG studies of small delphinids would improve our understanding of the variability within and among individuals, groups and populations and may help inform PAM studies.

Dive behavior of pantropical spotted dolphins has been previously studied in Hawaiian waters. Using suction cup-attached time-depth recorders, Baird et al. (2001) found mean daytime dive depths (of dives $>5 \mathrm{~m}$ ) of $12.8 \mathrm{~m}$, and mean durations of $1.43 \pm 0.25 \mathrm{~min}$. They also found that animals spent $88.5 \%$ of daytime hours in the upper $10 \mathrm{~m}$ of the water column. We found mean daytime 


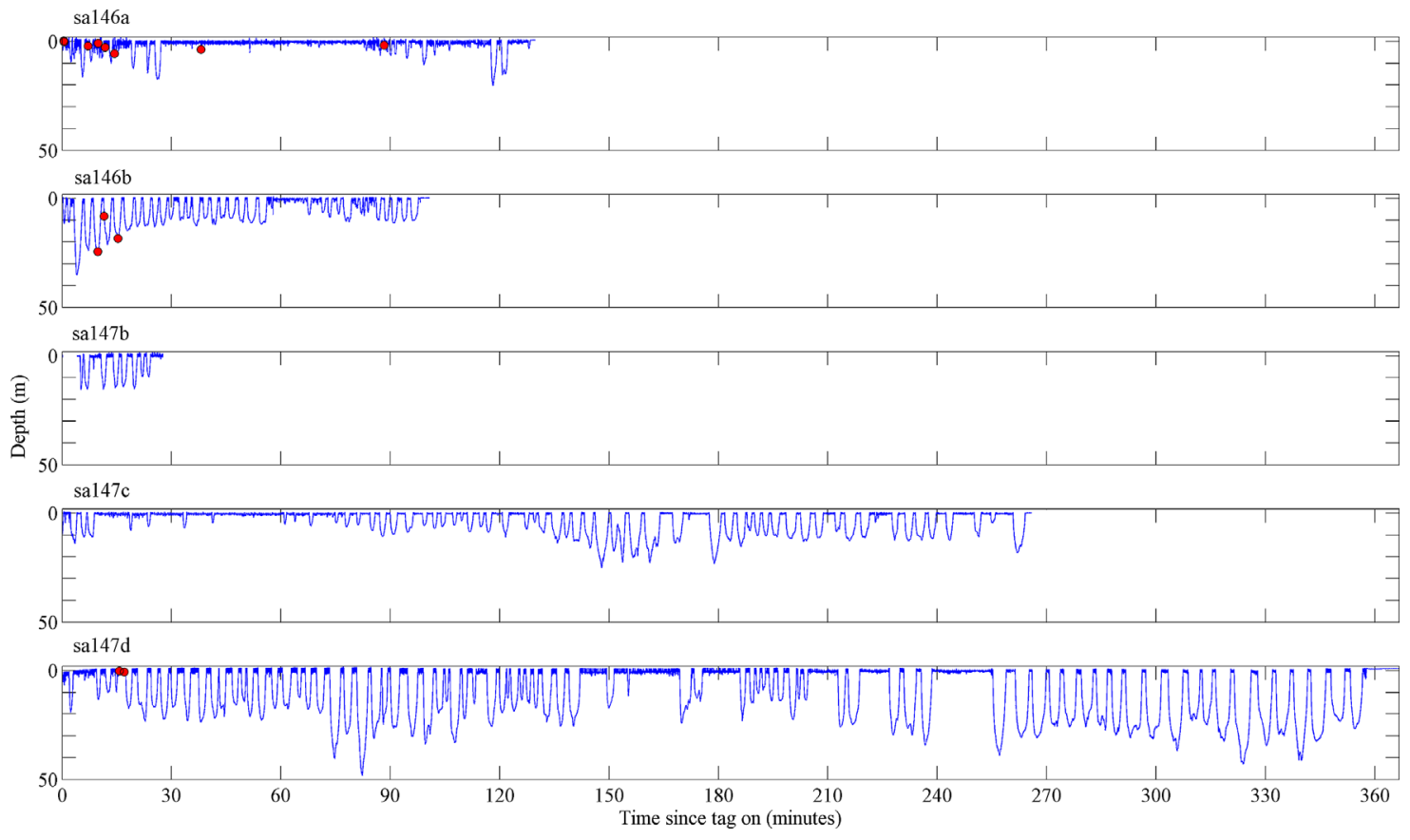

FIG. 3. (Color online) Dive profile for each tagged animal. Circles represent buzzes. For sa147d, sensor data were recorded for the full tag deployment (5:58), but audio was recorded for only 2:26.

dive depths of $16 \mathrm{~m}$, mean dive durations of $1.9 \pm 1.0 \mathrm{~min}$, and that animals spent $76.9 \%$ of time in the upper $10 \mathrm{~m}$ of the water column (Table I, Figs. 3 and 4). The slightly greater mean dive depth and dive duration reported here were largely due to a greater number of dives and overall deeper dives by one tagged animal, sa147d (Table I, Fig. 3). Mean dive depths for the other four tagged animals were much closer to the mean value reported by Baird et al. (2001) (Table I).

A new observation reported here and another advantage of the DTAG is the acoustic identification of potential echolocation-based foraging behavior by individual tagged spotted dolphins, indicated by the presence of apparent terminal buzzes preceded by echolocation clicks (Johnson et al., 2004; Aguilar Soto et al., 2008; Linnenschmidt et al., 2013; Wisniewska et al., 2016). Some feeding behavior was visually observed when the groups were first encountered in the present study, which is supported by the presence of echolocation clicks followed by terminal buzzes on some tags. However, not all tags recorded these terminal buzzes, nor were they abundant on the tags (Table I). Few foraging buzzes combined with shallow daytime dive statistics provide additional evidence that foraging by pantropical spotted dolphins occurs mainly at night (Baird

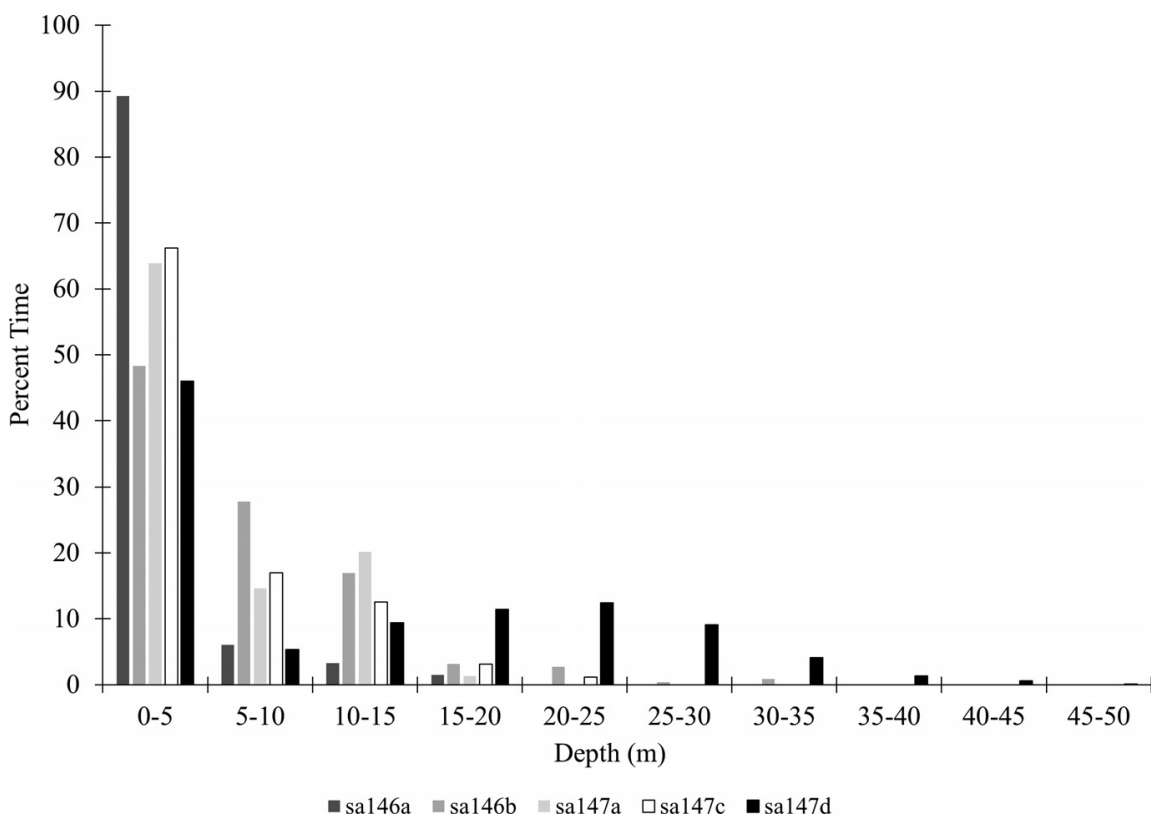

FIG. 4. Percent time spent in $5 \mathrm{~m}$ depth bins for each tagged animal. 
et al., 2001; Scott and Chivers, 2009). More detailed visual observations paired with tagging may help in defining finescale, daytime acoustic and dive behavior more thoroughly. In addition, DTAG deployments that extend through the night would help define diurnal patterns of dive and acoustic behavior.

Acoustic tag data are not only useful for studies of baseline behavior, but are also valuable for studying impacts of noise on cetaceans. However, until recently, DTAG deployments on small odontocetes have been limited by the comparatively large size of acoustic recording tags and the active behavior of the study animals. This is only the second published study to demonstrate deployment of acoustic tags on a small pelagic delphinid species (see Kaplan et al., 2014). Small pelagic delphinids have some of the highest densities for marine mammals at sea; they often travel in large groups of hundreds of animals (Rankin et al., 2008) and thus anthropogenic activities can expose many individuals (i.e., high numbers of "level B takes" in terms of the U.S. Marine Mammal Protection Act). This study demonstrates the feasibility of using tags to evaluate vocal and behavioral responses of these animals to increasing levels of anthropogenic noise, as well as the potential utility of acoustic recording tags to inform development of automated detectors/classifiers and improve interpretation of PAM data.

\section{ACKNOWLEDGMENTS}

This project was funded by the Office of Naval Research (award number: N000141110612; Program Manager Michael J. Weise), the WHOI Marine Mammal Center, and the Sawyer and Penzance Endowed Funds, with additional field time funded by grants through Cascadia Research Collective by the National Oceanographic Partnership Program (through the Alaska SeaLife Center) and the Pacific Islands Fisheries Science Center. Funding to support P.L.T. was also received from the MASTS pooling initiative (The Marine Alliance for Science and Technology for Scotland) and their support is gratefully acknowledged. MASTS is funded by the Scottish Funding Council (grant reference HR09011) and contributing institutions. Daniel Webster deployed the tags. Paul Nachtigall assisted with project planning. Employees of Cascadia Research Collective and other volunteers provided assistance in the field. Maxwell Kaplan provided assistance with MatLab scripts. Tagging took place under NMFS permit \# 15530 to Cascadia Research Collective and WHOI Institutional Animal Care and Use Committee approval (ID Number BI15245.00).

Aguilar Soto, N. A., Johnson, M. P., Madsen, P. T., Diaz, F., Domınguez, I., Brito, A., and Tyack, P. (2008). "Cheetahs of the deep sea: Deep foraging sprints in short-finned pilot whales off Tenerife (Canary Islands)," J. Anim. Ecol. 77, 936-947.

Ansmann, I. C., Goold, J. C., Evans, P. G. H., Simmonds, M., and Keith, S. G. (2007). "Variation in the whistle characteristics of short-beaked common dolphins, Delphinus delphis, at two locations around the British Isles," J. Mar. Biol. Assoc. U. K. 87, 19-26.

Aschettino, J. M., Baird, R. W., McSweeney, D. J., Webster, D. L., Schorr, G. S., Huggins, J. L., and West, K. L. (2012). "Population structure of melon-headed whales (Peponocephala electra) in the Hawaiian Archipelago: Evidence of multiple populations based on photo identification," Mar. Mamm. Sci. 28, 666-689.
Azevedo, A. F., Flach, L., Bisi, T. L., Andrade, L. G., Dorneles, P. R., and Lailson-Brito, J. (2010). "Whistles emitted by Atlantic spotted dolphins (Stenella frontalis) in southeastern Brazil," J. Acoust. Soc. Am. 127, 2646-2651.

Baird, R. W. (2016). The Lives of Hawai 'i's Dolphins and Whales: Natural History And Conservation (University of Hawai'i Press, Honolulu, HI), in press.

Baird, R. W., Ligon, A. D., Hooker, S. K., and Gorgone, A. M. (2001). "Subsurface and nighttime behaviour of pantropical spotted dolphins in Hawai' ‘i," Can. J. Zool. 79, 988-996.

Baird, R. W., Webster, D. L., Aschettino, J. M., Schorr, G. S., and McSweeney, D. J. (2013). "Odontocete cetaceans around the main Hawaiian Islands: Habitat use and relative abundance from small-boat sighting surveys," Aquat. Mamm. 39, 253-269.

Barlow, J. (2006). "Cetacean abundance in Hawaiian waters estimated from a summer/fall survey in 2002," Mar. Mamm. Sci. 22, 446-464.

Baumgartner, M. F., and Mussoline, S. E. (2011). "A generalized baleen whale call detection and classification system," J. Acoust. Soc. Am. 129, 2889-2902.

Bazúa-Durán, C., and Au, W. W. (2002). "The whistles of Hawaiian spinner dolphins," J. Acoust. Soc. Am. 112, 3064-3072.

Caldwell, M. C., and Caldwell, D. D. (1970). "Etiology of the chirp sounds emitted by the Atlantic bottlenose dolphin: A controversial issue," Underwater Nat. 6, 6-9.

Caretta, J. V., Oleson, E., Weller, D. W., Lang, A. R., Forney, K. A., Baker, J., Hanson, B., Martien, K., Muto, M. M., Orr, A. J., Huber, H., Lowry, M. S., Barlow, J., Lynch, D., Carswell, L., Brownell, R. L., Jr., and Mattila, D. K. (2014). "U.S. Pacific Marine Mammal Stock Assessments, 2013," NOAA Technical Memorandum NMFS-SWFSC-532, National Marine Fisheries Service, La Jolla, CA.

Charif, R. A., Waack, A. M., and Strickman, L. M. (2010). "Raven Pro 1.4 User's Manual," Cornell Lab of Ornithology, Ithaca, NY.

Courbis, S., Baird, R. W., Cipriano, F., and Duffield, D. (2014). "Multiple populations of pantropical spotted dolphins in Hawaiian waters," J. Hered. 105, 627-641.

Esch, H. C., Sayigh, L. S., Blum, J. E., and Wells, R. S. (2009). "Whistles as potential indicators of stress in bottlenose dolphins (Tursiops truncatus)," J. Mammal. 90, 638-650.

Hatch, L. T., Clark, C. W., Van Parijs, S. M., Frankel, A. S., and Ponirakis, D. W. "Quantifying loss of acoustic communication space for right whales in and around a U.S. National Marine Sanctuary," Conserv. Biol. 26, 983-994 (2012).

Hawkins, E. (2010). "Geographic variations in the whistles of bottlenose dolphins (Tursiops aduncus) along the east and west coasts of Australia," J. Acoust. Soc. Am. 128, 924-935.

Jensen, F. H., Bejder, L., Wahlberg, M., Aguilar Soto, N., Johnson, M., and Madsen, P. T. (2009). "Vessel noise effects on delphinid communication," Mar. Ecol. Progr. Ser. 395, 161-175.

Johnson, M., de Soto, N. A., and Madsen, P. T. (2009). "Studying the behaviour and sensory ecology of marine mammals using acoustic recording tags: A review," Mar. Ecol. Progr. Ser. 395, 55-73.

Johnson, M. P., Madsen, P. T., Zimmer, W. M. X., Aguilar de Soto, N., and Tyack, P. L. (2004). "Beaked whales echolocate on prey," Proc. R. Soc. London B Biol. Sci. 271, S383-S386.

Johnson, M. P., Madsen, P. T., Zimmer, W. M. X., Aguilar de Soto, N., and Tyack, P. L. (2006). "Foraging Blainville's beaked whales (Mesoploson densirostris) produce distinct click types matched to different phases of echolocation,” J. Exp. Biol. 209, 5038-5050.

Johnson, M. P., and Tyack, P. L. (2003). "A digital acoustic recording tag for measuring the response of wild marine mammals to sound," IEEE J. Ocean. Eng. 28, 3-12.

Kaplan, M. B., Mooney, T. A., Sayigh, L. S., and Baird, R. W. (2014). "Repeated call types in Hawaiian melon-headed whales (Peponocephala electra)," J. Acoust. Soc. Am. 136, 1394-1401.

Lammers, M. O., Au, W. W., and Herzing, D. L. (2003). "The broadband social acoustic signaling behavior of spinner and spotted dolphins," J. Acoust. Soc. Am. 114, 1629-1639.

Leatherwood, S., and Ljungblad, D. K. (1979). "Nighttime swimming and diving behavior of a radio-tagged spotted dolphin, Stenella attenuata," Cetology 34, 1-6.

Linnenschmidt, M., Teilmann, J., Akamatsu, T., Dietz, R., and Miller, L. A. (2013). "Biosonar, dive, and foraging activity of satellite tracked harbor porpoises (Phocoena phocoena),” Mar. Mam. Sci. 29, E77-E97. 
Marques, T. A., Thomas, L., Martin, S., Mellinger, D., Ward, J., Tyack, P., and Moretti, D. (2013). "Estimating animal population density using passive acoustics," Biol. Rev. 88, 287-309.

May-Collado, L. J., and Wartzok, D. (2008). "A comparison of bottlenose dolphin whistles in the Atlantic Ocean: Factors promoting whistle variation," J. Mammal. 89, 1229-1240.

Mooney, T. A., Au, W. W. L., Nachtigall, P. E., and Trippel, E. A. (2007). "Acoustic and stiffness properties of gillnets as they relate to small cetacean bycatch,” ICES J. Mar. Sci. 64, 1324-1332.

Morisaka, T., Shinohara, M., Nakahara, F., and Akamatsu, T. (2005). "Effects of ambient noise on the whistles of Indo-Pacific bottlenose dolphin populations," J. Mammal. 86, 541-546.

Oswald, J. N., Barlow, J., and Norris, T. F. (2003). "Acoustic identification of nine delphinid species in the eastern tropical Pacific Ocean," Mar. Mamm. Sci. 19, 20-037.

Oswald, J. N., Rankin, S., Barlow, J., and Lammers, M. O. (2007). "A tool for real-time acoustic species identification of delphinid whistles," J. Acoust. Soc. Am. 122, 587-595.

Rankin, S., Oswald, J. N., and Barlow, J. (2008). "Behavior of dolphins in the Pacific Ocean: Implications for using passive acoustic methods for population studies," Can. Acoust. 36, 88-92.

Risch, D., Clark, C. W., Dugan, P. J., Popescu, M., Siebert, U., and Van Parijs, S. M. (2013). "Minke whale acoustic behavior and multi-year seasonal and diel vocalization patterns in Massachusetts Bay, USA," Mar. Ecol. Progr. Ser. 489, 279-295.

Scott, M. D., and Cattanach, K. L. (1998). "Diel patterns in aggregations of pelagic dolphins and tunas in the eastern Pacific," Mar. Mamm. Sci. 14, 401-422.

Scott, M. D., and Chivers, S. J. (2009). "Movements and diving behavior of pelagic spotted dolphins," Mar. Mamm. Sci. 25, 137-160.
Smolker, R. A., Richards, A. F., Connor, R. C., and Pepper, J. W. (1992). "Sex differences in patterns of association among Indian Ocean bottlenose dolphins," Behaviour 123, 38-69.

Tyack, P. L., Zimmer, W. M. X., Moretti, D., Southall, B. L., Claridge, D. E., Durban, J. W., Clark, C. W., D'Amico, A., DiMarzio, N., Jarvis, S., McCarthy, E., Morrissey, R., Ward, J., and Boyd, I. L. (2011). "Beaked whales respond to simulated and actual navy sonar," PLoS One 6, e17009.

Van Parijs, S. M., Clark, C. W., Sousa-Lima, R. S., Parks, S. E., Rankin, S., Risch, D., and van Opzeeland, I. (2009). "Management and research applications of real-time and archival passive acoustic sensors over varying temporal and spatial scales," Mar. Ecol. Progr. Ser. 395, 21-36.

Wade, P. R., Watters, G. M., Gerrodette, T., and Reilly, S. B. (2007). "Depletion of spotted and spinner dolphins in the eastern tropical Pacific: Modeling hypotheses for their lack of recovery," Mar. Ecol. Progr. Ser. 343, 1-14.

Watwood, S. L., Miller, P. J. O., Johnson, M., Madsen, P. T., and Tyack, P. L. (2006). "Deep-diving foraging behaviour of sperm whales Physeter macrocephalus," J. Anim. Ecol. 75, 814-825.

Westgate, A. J., Read, A. J., Berggren, P., Koopman, H. N., and Gaskin, D. E. (1995). "Diving behaviour of harbour porpoises, Phocoena phocoena," Can. J. Fish. Aquat. Sci. 52, 1064-1073.

Wisniewska, D. M., Johnson, M., Teilmann, J., Rojano-Donate, L., Shearer, J., Sveegaard, S., Miller, L. A., Siebert, U., and Madsen, P. T. (2016). "Ultra-high foraging rates of harbor porpoises make them vulnerable to anthropogenic disturbance," Curr. Biol. 26, 1441-1446.

Zimmer, W. M., Johnson, M. P., Madsen, P. T., and Tyack, P. L. (2005). "Echolocation clicks of free-ranging Cuvier's beaked whales (Ziphius cavirostris)," J. Acoust. Soc. Am. 117, 3919-3927. 